\title{
$\underline{\mathbf{P}-100}$
}

\section{Antimicrobial Efficacy of Medicinal Plant Swertia Chirata}

\author{
Lwin Lwin Nyein ${ }^{1, *}$, Isma Syahril B Ismail ${ }^{2}$ and Nik Aiman Afiq Bin Nik Ab Rahman ${ }^{3}$ \\ ${ }^{I}$ Faculty of Medicine, University Teknologi MARA, 47000, Sg Buloh, Malaysia; ${ }^{2}$ Institute of Medical Molecular \\ Biotechnology, 47000, Sg Buloh, Malaysia; ${ }^{3}$ Faculty of Applied Sciences, University Teknologi MARA,72000,Kulua \\ Pihah, Malaysia; E-mail: llnyein674@salam.uitm.edu.my
}

Complementary and alternative medicine (CAM) is becoming increasingly popular and experienced a high growth all over the world. A medicinal plant, Swertia chirata, has been widely use as herbal medicine in Asian countries and some parts of the world. The aim of this study was to evaluate the antibacterial property of Swertia chirata. Plants were extracted using ethanol. Disc diffusion technique was used to detect antimicrobial activity. Crude extraction of whole plant showed significant antimicrobial activities against some Gram-positive and Gram-negative bacteria. Test materials at a concentration of $100 \mu \mathrm{g}$ disc $^{-1}$ were used to evaluate the antimicrobial activity and $30 \mu \mathrm{g}$ disc $^{-1}$ concentration of Kanamycin was used as positive control. Zone of inhibition against Staphylococcus aureus and Escherichia coli were 10mm and 8mm respectively. Minimum Inhibitory Concentration of the crude extract was determined by serial dilution technique which showed $64 \mu \mathrm{g} / \mathrm{ml}$ for Staphylococcus aureus and $128 \mu \mathrm{g} / \mathrm{ml}$ for Escherichia coli. Although the results obtained revealed inhibition against Staphylococcus aureus \& some Gram-positive \& negative bacteria, a further study need to be carried out to detect the active compounds of this highly potent plant. Moreover, problems of drug resistance leading to recurrent infections highlight a need to search for new compounds for treatment of microbial infections. Hence, Swertia chirata which possesses antimicrobial activity, hope will complement if not replace a standard antimicrobial drugs that will be of benefits to the health of the mankind.

Keywords: Swertia chirata, antibacterial, Complementary \& Alternative Medicine (CAM). 